\title{
Effect of immediate dentine sealing on the fracture strength of lithium disilicate and multiphase resin composite inlay restorations
}

van den Breemer, Carline R G ; Özcan, Mutlu ; Cune, Marco S ; van der Giezen, Rianne ; Kerdijk, Wouter ; Gresnigt, Marco M M

\begin{abstract}
PURPOSE Limited information is available on the effect of Immediate Dentin Sealing (IDS) on the fracture strength of indirect partial posterior restorations. This study evaluated the effect of IDS on the fracture strength and failure types of two indirect restorative materials. MATERIALS AND METHODS Standard MOD inlay preparations were made on sound molars $(\mathrm{N}=40, \mathrm{n}=10$ per group) and randomly divided into four groups to receive the inlay materials with and without the application of IDS: Group L-IDS-: Li2Si2O5 (Lithium disilicate, IPS e.max) without IDS; Group L-IDS+: Li2Si2O5 with IDS; Group MR-IDS-: Multiphase resin composite (MR, Lava Ultimate) without IDS; MR-IDS+: MR with IDS. Inlays made of L were etched with 5\% hydrofluoric acid, and MR inlays were silica coated. After silanization, they were cemented using adhesive resin cement (Variolink Esthetic DC). The specimens were thermo-mechanically aged $\left(1.2 \times 106\right.$ cycles, $1.7 \mathrm{~Hz}, 8000$ cycles, $\left.5-55^{\circ} \mathrm{C}\right)$ and then subjected to load to failure $(1 \mathrm{~mm} / \mathrm{min})$. Failure types and locations of debondings were classified. Data were statistically analyzed using ANOVA, Mann Whitney U-test and Chi-square tests $(\alpha=0.05)$. Two-parameter Weibull distribution values including the Weibull modulus, scale $(\mathrm{m})$ and shape $(0)$, values were calculated. RESULTS After aging conditions, no apparent changes were observed in marginal integrity but occlusal wear facets were more common with MR than with L $(\mathrm{p}<0.001)$. Material type and the application of IDS significantly affected the results $(\mathrm{p}=0.013)$. While group L-IDS- showed the lowest mean fracture strength $(1358 \pm 506 \mathrm{~N})$ among all groups $(\mathrm{p}<0.05)$, application of IDS significantly increased the results significantly (L-IDS+: $2035 \pm 403 \mathrm{~N})(\mathrm{p}=0.006)$. MR groups with and without IDS, did not show significant difference (MR-IDS-: 1861 \pm 423 , MR-IDS+: $1702 \pm 596$ N) $(p=0.498)$. When materials without IDS are compared, L showed significantly lower results than that of MR $(\mathrm{p}=0.035)$. With the application of IDS, no significant difference was noted between L and MR materials $(\mathrm{p}=0.160)$. Weibull distribution presented the highest shape (0) for L-IDS+ (5.66) compared to those of other groups (3.014.76). Neither the material type $(\mathrm{p}=0.830)$, nor the application of IDS $(\mathrm{p}=0.54)$ affected the severity of the failure types. In $95 \%$ of the cases, the IDS layer left adhered on the tooth surface after fracture tests. In groups where no IDS was used, resin cement remained on the tooth surface in $44 \%$ of the cases $(p=0.001)$. No significant differences were observed between the materials with respect to cement remnants or IDS after fracture $(\mathrm{p}=0.880)$. The incidence of repairable failure types $(83 \%)$ was more common with L than with MR $(75 \%)$ material $(p>0.05)$. CONCLUSION Immediate dentin sealing improves adhesion, and thereby the fracture strength of inlays made of lithium disilicate but not that multiphase resin composite.
\end{abstract}

DOI: https://doi.org/10.1016/j.jmbbm.2017.04.002

Posted at the Zurich Open Repository and Archive, University of Zurich

ZORA URL: https://doi.org/10.5167/uzh-145984

Journal Article

Accepted Version 


\section{(c) $\mathbb{\Theta \Theta}$}

The following work is licensed under a Creative Commons: Attribution-NonCommercial-NoDerivatives 4.0 International (CC BY-NC-ND 4.0) License.

Originally published at:

van den Breemer, Carline R G; Özcan, Mutlu; Cune, Marco S; van der Giezen, Rianne; Kerdijk, Wouter; Gresnigt, Marco M M (2017). Effect of immediate dentine sealing on the fracture strength of lithium disilicate and multiphase resin composite inlay restorations. Journal of the Mechanical Behavior of Biomedical Materials, 72:102-109. DOI: https://doi.org/10.1016/j.jmbbm.2017.04.002 
Effect of immediate dentine sealing on the fracture strength of lithium disilicate and

multiphase resin composite inlay restorations

Carline R.G. van den Breemer, ${ }^{a,{ }^{*}}$ Mutlu Özcan, ${ }^{\mathrm{a}, \mathrm{b}}$ Marco S. Cune, ${ }^{\mathrm{a}, \mathrm{c}}$ Rianne van der Giezen, ${ }^{a}$

Wouter Kerdijk, ${ }^{d}$ Marco M.M. Gresnigt ${ }^{a}$

aUniversity Medical Center Groningen, The University of Groningen, Groningen, Center for Dentistry and Oral Hygiene, Department of Fixed and Removable Prosthodontics, The Netherlands

bUniversity of Zurich, Dental Materials Unit, Center for Dental and Oral Medicine, Clinic for Fixed and Removable Prosthodontics and Dental Materials Science, Zurich,

Switzerland

cSt. Antonius Hospital Nieuwegein, Department of Oral and Maxillofacial Surgery, Prosthodontics and Special Dental Care, Nieuwegein, The Netherlands 'University Medical Center Groningen, The University of Groningen, Groningen, Center for Dentistry and Oral Hygiene, Department of Public and Individual Oral Health, The Netherlands

Short title: Effect of immediate dentin sealing on durability of inlays

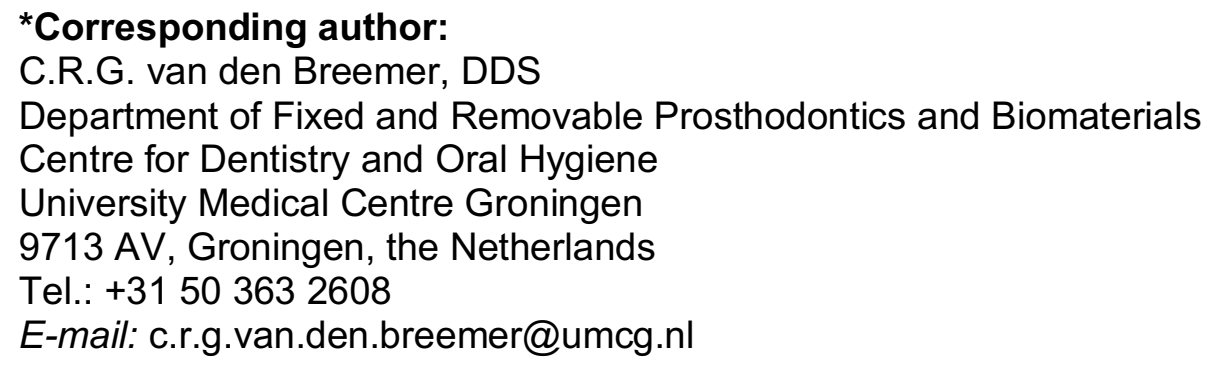




\section{ABSTRACT}

Objectives. Limited information is available on the effect of Immediate Dentin Sealing (IDS) on the fracture strength of indirect partial posterior restorations. This study evaluated the effect of IDS on the fracture strength and failure types of two indirect restorative materials.

Methods. Standard inlay preparations were made on sound molars $(N=40, n=10$ per group) and randomly divided into four groups to receive the inlay materials with and without the application of IDS: Group L-IDS: $\mathrm{Li}_{2} \mathrm{Si}_{2} \mathrm{O}_{5}$ (Lithium disilicate, IPS e.max) without IDS; Group L-IDS': $\mathrm{Li}_{2} \mathrm{Si}_{2} \mathrm{O}_{5}$ with IDS; Group MR-IDS: Multiphase resin composite (MRC, Lava Ultimate) without IDS; MR-IDS+: MR with IDS. Inlays made of L were etched with $5 \%$ hydrofluoric acid, and MR silica coated. After silanization, they were cemented using adhesive resin cement (Variolink Esthetic DC). The specimens were thermo-mechanically aged $\left(1.2 \times 10^{6}\right.$ cycles, $1.7 \mathrm{~Hz}, 8000$ cycles, $\left.5-55^{\circ} \mathrm{C}\right)$ and then subjected to load to failure $(1 \mathrm{~mm} / \mathrm{min})$. Failure types and locations of debondings were classified. Data were statistically analyzed using ANOVA, Mann Whitney U-test and Chi-square tests $(\alpha=0.05)$. Two-parameter Weibull distribution values including the Weibull modulus, scale $(m)$ and shape $(0)$, values were calculated.

Results. After aging conditions, no apparent changes were observed in marginal integrity but occlusal wear facets were more common with MR than with $L(p<0.001)$. Material type and the application of IDS significantly affected the results $(p=0.013)$. While group L-IDS- showed the lowest mean fracture strength $(1358 \pm 506 \mathrm{~N})$ among all groups $(p<0.05)$, application of IDS significantly increased the results significantly (LIDS $\left.{ }^{+}: 2035 \pm 403 N\right)(p=0.006)$. MR groups with and without IDS, did not show significant difference (MR-IDS: $1861 \pm 423$, MR-IDS $\left.^{+}: 1702 \pm 596 \mathrm{~N}\right)(p=0.498)$. When materials without IDS are compared, L-IDS- showed significantly lower results than that of MRIDS- $^{-}(p=0.035)$. With the application of IDS, no significant difference was noted between 
$L$ and MR materials $(p=0.160)$. Weibull distribution presented the highest shape $(0)$ for $\mathrm{L}-I D S^{+}(5.66)$ compared to those of other groups (3.01-4.76). Neither the material type $(p=0.830)$, nor the application of IDS $(p=0.54)$ affected the severity of the failure types. In $95 \%$ of the cases, the IDS layer was left adhered on the tooth surface after fracture tests. In groups where no IDS were used, resin cement remained on the tooth surface in $44 \%$ of the cases $(p=0.001)$. No significant differences were observed between the materials with respect to cement remnants or IDS after fracture $(p=0.880)$. The incidence of repairable failure types (83\%) was more common with $L$ than with MR $(75 \%)$ material $(p>0.05)$.

Significance. Immediate dentin sealing improves adhesion, and thereby the fracture strength of inlays made of $\mathrm{Li}_{2} \mathrm{Si}_{2} \mathrm{O}_{5}$ but not that multiphase resin composite.

Keywords: Cement; Ceramic; Cyclic loading; Fracture strength; Immediate dentin sealing; Indirect composite; Inlay; Lithium disilicate; Multiphase resin composite. 


\section{Introduction}

Minimally invasive dentistry strives for preservation of enamel as much as possible since removing large amount of tooth structure has an adverse effect on the pulp and may lead to vitality loss [1,2]. Current restorative concepts are based on bio-emulation philosophy that is to restore teeth mimicking both the biomechanical and structural properties of a natural tooth [3-5]. By taking biology, mechanics, function and aesthetics into account, a harmonious and natural restorative result could be achieved [6]. A restoration following these principles can either be made from a direct or an indirect restorative material, where the former is chosen when restoration of morphology and function is difficult to restore $[4,7,8]$. A restoration made of an indirect restorative material that suits a minimally invasive preparation is a so-called partial restoration. In the application of indirect partial restorations several components are relevant, namely the material, adhesive cementation to dentin/ enamel, and the bonding procedures.

Indirect partial restorations could be made of various materials. Gold onlays are reliable restorative options with success rate of $92 \%$ over nine years [6,9-11]. Studies on ceramic indirect restorations show survival rate between 90 and $100 \%$ after five years $[6,9,12-14]$, and a success rate between 89 and $91 \%$ after ten years $[7,14]$. On the other hand, multiphase resin composite restorations present three-year survival rate of $100 \%$ [15], while others reported a two-year survival rate of $90 \%$ [15], with an average annual failure rate of $0-11.8 \%$ [12].

Limited information is available on the clinical survival of indirect resin composites [1418]. Likewise, little is known on the multiphase resin composite (MR, Lava Ultimate, 3M ESPE) but it is claimed that restorations made of this material have comparable fatigue resistance with those made of ceramics [19]. The most common cause of failure of inlays made of either ceramic or resin composite is fracture [11,12,14,20-23]. Such fractures are primarily within the restorative material, followed by fractures in the tooth 
$[7,16,20,21]$. In fact, adhesive cementation provides chemical and micro-mechanical attachment of the restoration to the tooth and re-establishes the integrity of the tooth and circumvents microleakage $[2,24,25]$. In that respect, sealing the dentin immediately after tooth preparation using a dentin bonding agent to the freshly cut dentin, the so called 'immediate dentin sealing (IDS)', was advocated in early 1990s [26]. Several studies have shown that application of IDS after tooth preparation ensure improved bond strength of resin based materials $[5,27,28]$ and ceramic restorations to dentin [5,28-34]. However, it is ambiguous whether the application of IDS would have a similar positive effect on the fracture strength of inlays.

The objective of this study therefore was to compare the fracture strength of lithium disilicate $\left(\mathrm{Li}_{2} \mathrm{Si}_{2} \mathrm{O}_{5}\right)$ and multiphase resin composite material with and without the application of IDS. The hypothesis tested was that the presence of IDS would positively contribute to the fracture strength of the glass ceramic and the indirect resin composite material compared to conventional adhesive cementation.

\section{Material and methods}

\subsection{Specimen preparation}

The brands, types, manufacturers, chemical compositions and batch numbers of the materials used for the experiments are listed in Table 1. Schematic description of the experimental design is presented in Fig. 1.

Sound human molars $(\mathrm{N}=40)$ of similar size, free of restorations, fractures, caries and root canal treatment were selected from a pool of recently extracted teeth ( $<6$ months). All teeth were screened on the presence of cracks through blue light illumination and those with cracks were eliminated. The selected teeth were placed in polyvinylchloride (PVC) tubes (height: $10 \mathrm{~mm}$; diameter: $15 \mathrm{~mm}$ ) and filled with polymethylmethacrylate (Probase Cold, Ivoclar Vivadent, Schaan, Liechtenstein) up to $1 \mathrm{~mm}$ below the cementenamel junction (CEJ). After photographs were made from each specimen, they were 
scanned using an intraoral scanner (Lava 3M ST scanner, 3M ESPE, St. Paul, USA). The scanned images served for the definitive form of the restorations after preparation. Specimens were stored in distilled water at $37^{\circ} \mathrm{C}$ during the experiments.

Teeth were randomly divided into four groups to receive the inlay materials with and without the application of IDS: Group L-IDS: $\mathrm{Li}_{2} \mathrm{Si}_{2} \mathrm{O}_{5}$ (Lithium disilicate, IPS e.max, Ivoclar Vivadent, Schaan, Liechtenstein) without IDS; Group L-IDS': $\mathrm{Li}_{2} \mathrm{Si}_{2} \mathrm{O}_{5}$ with IDS; Group MR-IDS: Multiphase resin composite (MRC, Lava Ultimate, 3M ESPE, St. Paul, USA) without IDS; MR-IDS+: MR with IDS.

Standard preparations were made in each tooth (bucco-lingual width: $5 \mathrm{~mm}$, depth: 2 $\mathrm{mm}$ from the fissure, approximal outline: $1 \mathrm{~mm}$ above the CEJ) using different burs (no. 6856,8856, TPS2-8, TPS2-9, Komet Dental, Lemgo, Germany). The width of the preparation determined the diameter of the remaining walls, depending on the size of the tooth. The axial walls were prepared with divergence of $<6 \%$ to eliminate undercuts. The dimensions of the preparations were checked using an electronic caliper and adjusted after the preparation where needed.

\subsection{Immediate dentin sealing}

In groups L-IDS ${ }^{+}$and MR-IDS ${ }^{+}$, IDS was applied immediately after tooth preparation. A self-etching primer (Clearfil SE Bond, Kuraray Co., Tokyo, Japan) was actively applied to the dentin surface for $20 \mathrm{~s}$, air-dried gently with oil-free air, until dry and glossy appearance of the dentin was maintained. Hereafter, an adhesive resin (Clearfil SE Bond, Kuraray Co.) was applied with microbrush on the dentin only and photopolymerized for $10 \mathrm{~s}$ using an LED polymerization device (Bluephase 20i, Ivoclar Vivadent) from a distance of $2 \mathrm{~mm}$. Then, flowable resin composite (Tetric Evoflow, Ivoclar Vivadent) was applied on the dentin surface in order to increase the thickness and protect the IDS layer and photo-polymerized for $40 \mathrm{~s}$. The output of the polymerization device was $>1000 \mathrm{~mW} / \mathrm{cm}^{2}$ throughout the experiment verified by a radiometer (Bluephasemeter, Ivoclar Vivadent). After application of glycerine gel 
(Johnson \& Johnson, Sezanne, France), the surface was again photo-polymerized for 40 s. Excess adhesive resin on enamel was removed using a fine grid diamond bur (no. 862EF, Komet Dental, Lemgo, Germany) and rubbers (no. 9619, Komet Dental) under an operatory microscope (x10 Opmipico, Zeiss, Oberkochen, Germany). Digital photos were made from 5 sides and then the teeth were scanned again using an intraoral scanner (Lava 3M ST Scanner, 3M ESPE) after which the STL files were sent to the dental laboratory.

\subsection{Temporary and permanent restorations}

In groups L-IDS ${ }^{+}$and MR-IDS ${ }^{+}$, glycerine gel (Johnson \& Johnson) was applied on the IDS layer before placing the provisional restorations in order to prevent adhesion between IDS and the provisional material (Protemp 4, 3M ESPE) [35]. Provisional restorations were adjusted using polishing discs (Sof-Lex Contouring and Polishing Disks, 3M ESPE) and luted with temporary cement (Durelon, 3M ESPE). Specimens were stored in distilled water at $37^{\circ} \mathrm{C}$ for 3 weeks.

One dental technician fabricated lithium disilicate inlays according to the instructions of the manufacturer. Ceramic restorations were milled in wax and then pressed and glazed in a ceramic oven (Programat EP5000, Ivoclar Vivadent) while multiphase resin composite restorations were milled in a 5-axis milling machine (Lava 3M CNC 500, 3M ESPE) and glazed.

\subsection{Adhesive cementation}

After removing the provisional restorations, each tooth was cleaned with pumice and the fit of the ceramic restorations was controlled using an optical microscope (x10, OpmiPico, Zeiss). A dual-polymerized resin composite cement (Variolink Esthetic DC, Ivoclar Vivadent) was used for cementation of the ceramic restorations. A two-step bonding procedure (Adhese Universal, Ivoclar Vivadent) with separate conditioning of the IDS layer was employed to ensure adhesion. 
Cementation surfaces of the ceramic inlays were conditioned using $5 \%$ hydrofluoric acid (IPS Ceramic etching gel, Ivoclar Vivadent) for $20 \mathrm{~s}$, rinsed with water and a neutralizing powder (IPS Ceramic neutralizing powder, Ivoclar Vivadent). The restorations were ultrasonically cleaned (Emag, Valkenswaard, the Netherlands) in distilled water for 5 minutes. Hereafter the restorations were dried, silanized (Monobond Plus, Ivoclar Vivadent) and hot air-dried for $60 \mathrm{~s}$. Adhesive resin was applied (Adhese Universal, Ivoclar Vivadent) to the ceramic surfaces, air-thinned but not photopolymerized.

Cementation surfaces of the resin composite restorations were tribochemically treated (CoJet Sand, 3M ESPE) for $10 \mathrm{~s}$ with nozzle angle of $45^{\circ}$, distance of $10 \mathrm{~mm}$ at 2 bar pressure using a chairside air-abrasion device (Dento-Prep, RØNVIG A/S, Daugaard, Denmark). Silane coupling agent (ESPE-SIL, 3M ESPE) was applied on the adhesion surface, left to react for 5 minutes and hot air-dried for 2 minutes. Adhesive resin was then applied (Adhese Universal, Ivoclar Vivadent) with a microbrush on the composite surface.

In groups L-IDS- and MR-IDS-, teeth were etched with $37 \% \mathrm{H}_{3} \mathrm{PO}_{4}$ (enamel: $30 \mathrm{~s}$, dentin: $10 \mathrm{~s}$, Total-etch, Ivoclar Vivadent) and rinsed with copious water for $30 \mathrm{~s}$. In groups L-IDS ${ }^{+}$and MR-IDS ${ }^{+}$, the IDS layer was tribochemically treated (CoJet, 3M, ESPE) using a chairside air-abrasion device (Dento-PrepTM, RØNVIG A/S, Daugaard, Denmark) for $4 \mathrm{~s}$ with nozzle angle of $45^{\circ}$, distance of $10 \mathrm{~mm}$ at 2 bar pressure. Enamel was etched with $37 \% \mathrm{H}_{3} \mathrm{PO}_{4}$ for $30 \mathrm{~s}$, rinsed and air-dried. Silane (ESPE-Sil, 3M ESPE) was applied one coat on the silica-coated IDS surfaces left to react for 5 minutes. Subsequently, adhesive resin (Adhese Universal, Ivoclar Vivadent) was applied to the whole preparation using a microbrush for $20 \mathrm{~s}$.

Inlay restorations were cemented using dual-poymerized resin composite cement (Variolink Esthetic DC, Ivoclar Vivadent) and excess cement was removed with microbrushes. Glycerine gel (Johnson \& Johnson) was applied at the margins of the 
restorations and photo-polymerized for $40 \mathrm{~s}$ from labial, lingual and incisal sides (Bluephase, Ivoclar Vivadent, light output: $\geq 1000 \mathrm{~mW} / \mathrm{cm}^{2}$ ). Margins were polished using soflex discs (Sof-lex Contouring and polishing disks, 3M ESPE) and rubber burs (no. 9619, Greenies, Komet Dental).

\subsection{Aging and fracture test}

All specimens were artificially aged in a chewing simulator (SD Mechatronik CS-4.8 Chewing Simulator, Feldkirchen-Westerham, Germany) using a ceramic antagonist sphere $(50 \mathrm{~N})$ on the occlusal plane for $1.2 \times 10^{6}$ cycles, $\left.1.7 \mathrm{~Hz}\right)$ and hydrolytically aged (x8000 cycles between $5-55^{\circ} \mathrm{C}$ ) in distilled water. Changes in marginal gap and occlusal wear were evaluated after thermo-mechanical loading under optical microscope (x40, Leica Wild Heerbrugg, M3Z Schott Zeiss KL200).

The specimens were then mounted in the jig of the Universal Testing Machine (810 Material Test System, MTS, Eden Prairie, USA) and loaded with $8 \mathrm{~mm}$ steel ball perpendicular to the occlusal surface at a crosshead speed of $1 \mathrm{~mm} / \mathrm{min}$. The maximum force to produce fracture was recorded.

\subsection{Failure analysis}

Failure sites were initially observed using an optical microscope (Leica Wild Heerbrugg, M3Z Schott Zeiss KL200) at x40 magnification and classified as an ordinal variable with increasing severity as follows: Score 1: Fracture of the inlay; Score 2: Fracture of the inlay and enamel; Score 3: Fracture of the inlay, enamel and dentin, Score 4: Root fracture. The presence of the cement or IDS was also noted on the tooth after fracture. Failure types were further classified depending on their reparability where root fractures and deep subgingival fractures were scored as not repairable. Additionally, representative specimens from each group were sputter-coated with a $3 \mathrm{~nm}$ thick layer of gold (80\%) / palladium (20\%) (90 s, 45mA; Balzers SCD 030, Balzers, Liechtenstein) and analyzed using cold field emission Scanning Electron Microscope (SEM) (LEO 440, Electron Microscopy Ltd, Cambridge, United Kingdom). 


\subsection{Statistical analysis}

Data were analyzed using a statistical software package (SPSS 22, PASW statistics 18.0.3, Quarry Bay, Hong Kong, China). Kolmogorov-Smirnov and Shapiro-Wilk tests were used to test normal distribution of the data. As the data were normally distributed, 2-way analysis of variance (ANOVA) and Tukey`s tests were applied to analyze possible differences between the groups for the parameters of material type and the effect of IDS on fracture strength results. Mann-Whitney $U$ and Chi-Square tests were used to investigate differences in failure types between the experimental groups. Maximum likelihood estimation without a correction factor was used for 2-parameter Weibull distribution, including the Weibull modulus, scale $(m)$ and shape (o), to interpret predictability and reliability of adhesion (Minitab Software V.16, State College, PA, USA). $P<0.05$ was considered to be statistically significant in all tests.

\section{Results}

After aging conditions, no apparent changes were observed in marginal integrity but occlusal wear facets were more common with MR than with L (Figs. 2a-b) $(\square 2(1)=18.027, p<0.001)$.

Mean fracture strength results showed significant difference between the groups $(p<0.05)$. Material type and the application of IDS significantly affected the results (ANOVA; $F(1,34)=6.94, p=0.013)$.

While group L-IDS- showed the lowest mean fracture strength $(1358 \pm 506 \mathrm{~N})$ among all groups $(p<0.05)$, application of IDS significantly increased the results significantly ( $L-$ IDS $\left.^{+}: 2035 \pm 403 \mathrm{~N}\right)(\mathrm{t}(16)=3.164 ; \mathrm{p}=0.006)$. MR groups with and without IDS, did not show significant difference (MR-IDS: $1861 \pm 423, M^{-}-I^{+}$: $\left.1702 \pm 596 \mathrm{~N}\right)(\mathrm{t}(18)=0.691$, $\mathrm{p}=0.498$ ) (Table 2). When materials without IDS are compared, L-IDS- showed significantly lower results than that of MR-IDS $^{-}(t(16)=2.30 ; p=0.035)$. With the 
application of IDS, no significant difference was noted between $L$ and MR materials $(t(18)=1.47 ; p=0.160)$.

Weibull distribution presented the highest shape (0) for L-IDS ${ }^{+}$(5.66) compared to those of other groups (3.01-4.76) (Fig. 1).

Neither the material type (Mann-Whitney test; $U=173 ; p=0.830$ ), nor the application of IDS (Mann-Whitney test; $U=160 ; p=0.54$ ) affected the severity of the failure types (Table 3). In $95 \%$ of the cases, the IDS layer was left adhered on the tooth surface after fracture tests. In groups where no IDS were used, resin cement remained on the tooth surface in $44 \%$ of the cases $(\square 2(1)=11.77, p=0.001)$ (Figs. 3a-b). No significant differences were observed between the materials with respect to cement remnants or IDS after fracture $(\square 2(1)=0.023 ; p=0.880)$. The incidence of repairable failure types $(83 \%)$ was more common with $L$ than with $M R(75 \%)$ material $(p>0.05)$.

\section{Discussion}

This study evaluated whether the application of immediate dentin sealing (IDS) could improve fracture strength of lithium disilicate and multiphase resin composite inlays in molar teeth after aging. The application of IDS was previously not investigated in posterior teeth restored with ceramic or indirect resin composites. Based on the results of the present study, since IDS significantly increased the fracture strength of ceramic inlays but not the composite ones, the hypothesis could be partially accepted.

Clinical studies on partial ceramic posterior restorations without the application of IDS show survival probability of 80 to $95 \%$ over a period of 10 years [14,36]. Reported failures were due to fracture of the ceramic material and reduction in margin quality [37]. Bulk fracture of ceramic materials in general is still a major reason for failure due to inherent fragility of the ceramics [14]. Hence, it is important to improve the fracture strength of the ceramic materials especially in the posterior teeth. 
In a recent in vitro study, IDS application significantly increased the fracture strength of laminate veneers made of lithium disilicate bonded to large dentin substrates [38]. In this study, not the resin composite but the ceramic inlays benefitted from IDS application. IDS application in combination with flowable resin composite, could decrease the space available for the indirect restoration that may eventually also decrease the cohesive strength of the restorative material. In the multiphase resin composite group, most failures were restoration fractures. Manufacturer recommendations of this material state that $1.5 \mathrm{~mm}$ or more space should be available at the isthmus height. In this study, a depth of $2 \mathrm{~mm}$ from the fissure was established but due to the application of IDS with the flowable resin composite, the depth could have been decreased. The strength of multiphase resin composite could increase with increased isthmus dimensions that need further investigations.

Average bite forces range between 20 to $1000 \mathrm{~N}$ but during normal function, forces do not exceed $270 \mathrm{~N}$ [40]. Only some patients with signs of bruxism express higher masticatory forces [39]. With an average load to failure value of $1835 \mathrm{~N}$ almost all the restorations fulfilled the maximum expected chewing forces of $1000 \mathrm{~N}$. Mean fracture strength results of this study $(1300-2000 \mathrm{~N})$ are not consistent with previous studies where 1600 to $2600 \mathrm{~N}$ were reported $[24,28,40]$. However, it has to be noted that in those studies no aging procedures were performed. The current study employed thermo-mechanical cyclic loading $\left(50 \mathrm{~N}, 1.2 \times 10^{6}\right.$ cycles, $\left.1.7 \mathrm{~Hz}, 5-55^{\circ} \mathrm{C}\right)$ that was postulated to represent five years of clinical function [41]. During such aging process, different levels of degradation processes could be expected for the ceramic and resin composite materials. Interfaces between the resin composite matrix and the silica coated inorganic fillers are more prone to hydrolytic degradation mainly at the adhesive interface [42]. The materials used in this study did not show significant difference in fracture strength in conditions where no IDS was applied. Studies on fracture strength 
using similar materials presented comparable values (1250 to $1580 \mathrm{~N}$ ) [24], or higher values (1614 to $2522 \mathrm{~N}$ ) being more in favour of ceramic materials [43].

In this study, multiphase resin composite inlays showed significantly more visible occlusal wear than the lithium disilicate ones. Such wear facets may initiate crack formation already during cyclic loading. Typically, the antagonist material used in such aging procedures is made of enamel or ceramic $[42,45]$. In this study, ceramic was used as an antagonist sphere. When antagonist materials are compared, ceramic ones cause more wear $(130-265 \mu \mathrm{m})$ than enamel $(120-199 \mu \mathrm{m})$, especially when the tested material is composite $[41,44]$. The results may change when antagonist material is enamel or metal. Yet, the choice of ceramic may represent a worse-case scenario.

In the failure analysis it was noted that In the majority of the specimens IDS layer was still intact on the dentin surfaces after the fracture test. This implies that adhesion to dentin was in fact more stable than the adhesion of the resin composite to the intaglio surfaces of the inlays. When IDS was not used, the cement remained on the tooth in $44 \%$ of the cases. Thus, employing an IDS layer, the weakest link remains to be at the IDS-cement-restoration complex. In fact, the IDS layer was conditioned using tribochemical silica-coating and silanization in order to increase the adhesion between prepolymerized IDS and the resin cement. Apparently, this interface suffered form aging during thermo-mechanical loading. In this study, after removal of temporary restorations, IDS layer was not re-created as this procedure could affect the precise fit of the inlay. Surface conditioning methods with silane coupling agents other than 3methacryloxypropyl trimethoxysilane coupling agent, y-MPS, could increase the adhesion that needs to be further elaborated [45].

In earlier studies on veneers, the weakest link in adhesion seemed to be between the adhesive layer and the dentin [46-48]. In this study however with posterior inlays, adhesion to dentin was not impaired in the majority of the cases. This could be due to axial loading only whereas in laminates both shear and tensile forces are exposed to 
the bonded interfaces. Nevertheless, also based on the high incidence of repairable failures, higher survival of the tooth itself could be expected with both materials tested for inlay restorations in molars.

\section{Conclusions}

From this study, the following could be concluded:

1. The application of immediate dentin sealing significantly improved the fracture resistance of lithium disilicate inlays bonded to dentin.

2. Occlusal wear was more common with the multiphase resin composite inlays than with lithium disilicate after thermo-mechanical aging.

3. Multiphase resin composite inlays showed more irreparable failures and immediate dentin sealing did not improve its fracture resistance.

\section{Acknowledgements}

The authors acknowledge Mr. P. Oosterwijk, B. van der Wal and A. van Elk of Dental Laboratory Oosterwijk/Elysee, Groningen, The Netherlands, for fabricating the ceramic inlays, and extend their gratitude to Ivoclar Vivadent, Schaan, Liechtenstein, 3M ESPE, St. Paul, USA, and Kerr, Orange, CA, USA for generous provision of some of the materials used in this study.

\section{Conflict of interest}

The authors did not have any commercial interest in any of the materials used in this study. 


\section{References}

[1] Langeland K, Langeland LK. Pulp reactions to cavity and crown preparation. Aust Dent J 1970;15:261-76.

[2] Dahl BL. Dentine/pulp reactions to full crown preparation procedures. J Oral Rehabil $1977 ; 4: 247-54$

[3] Sarikaya M. An introduction to biomimetics: a structural viewpoint. Microsc Res Tech $1994 ; 27: 360-75$

[4] Meyer A Jr, Cardoso LC, Araujo E, Baratieri LN. Ceramic inlays and onlays: clinical procedures for predictable results. J Esthet Restor Dent 2003;15:338-52.

[5] Magne P. Composite resins and bonded porcelain: the postamalgam era? J Calif Dent Assoc 2006;34:135-47.

[6] Gandjour A, Kerschbaum T, Reis A, Lauterbach KW. Technology assessment in dentistry: a comparison of the longevity and cost-effectiveness of inlays. Int $\mathrm{J}$ Technol Assess Health Care 2005;21:319-25.

[7] Sjogren G, Molin M, van Dijken JW. A 10-year prospective evaluation of CAD/CAMmanufactured (Cerec) ceramic inlays cemented with a chemically cured or dual-cured resin composite. Int J Prosthodont 2004;17:241-6.

[8] Hopp CD, Land MF. Considerations for ceramic inlays in posterior teeth: a review. Clin Cosmet Investig Dent 2013;5:21-32.

[9] Bergman MA. The clinical performance of ceramic inlays: a review. Aust Dent $\mathrm{J}$ 1999;44:157-68.

[10] Donly KJ, Jensen ME, Triolo P, Chan D. A clinical comparison of resin composite inlay and onlay posterior restorations and cast-gold restorations at 7 years. Quintessence Int 1999;30:163-8.

[11] Hayashi M, Yeung CA. Ceramic inlays for restoring posterior teeth. Aust Dent J 2004;49:60. 
[12] Hickel R, Manhart J. Longevity of restorations in posterior teeth and reasons for failure. J Adhes Dent 2001;3:45-64.

[13] Guess PC, Selz CF, Steinhart YN, Stampf S, Strub JR. Prospective clinical splitmouth study of pressed and CAD/CAM all-ceramic partial-coverage restorations: 7-year results. Int J Prosthodont 2013;26:21-5.

[14] Morimoto S, Rebello de Sampaio FB, Braga MM, Sesma N, Özcan M. Survival rate of resin and ceramic inlays, onlays, and overlays: a systematic review and metaanalysis. J Dent Res 2016;95:985-94.

[15] Dukic W, Dukic OL, Milardovic S, Delija B. Clinical evaluation of indirect composite restorations at baseline and 36 months after placement. Oper Dent 2010:35:156-64.

[16] Manhart J, Scheibenbogen-Fuchsbrunner A, Chen HJ, Hickel R. A 2-year clinical study of composite and ceramic inlays. Clin Oral Investig 2000;4:192-8.

[17] Fasbinder DJ, Dennison JB, Heys DR, Lampe K. The clinical performance of CAD/CAM-generated composite inlays, J Am Dent Assoc 2005;136:1714-23.

[18] Lange RT, Pfeiffer P. Clinical evaluation of ceramic inlays compared to composite restorations. Oper Dent 2009;34:263-72.

[19] Magne P, Knezevic A. Simulated fatigue resistance of composite resin versus porcelain CAD/CAM overlay restorations on endodontically treated molars. Quintessence Int 2009;40:125-33.

[20] Otto T, De Nisco S. Computer-aided direct ceramic restorations: a 10-year prospective clinical study of Cerec CAD/CAM inlays and onlays. Int $\mathrm{J}$ Prosthodont 2002;15:122-8.

[21] Ahlers MO, Morig G, Blunck U, Hajto J, Probster L, Frankenberger R. Guidelines for the preparation of CAD/CAM ceramic inlays and partial crowns. Int J Comput Dent 2009;12:309-25. 
[22] Yildiz C, Vanlioglu BA, Evren B, Uludamar A, Kulak-Ozkan Y. Fracture resistance of manually and CAD/CAM manufactured ceramic onlays. J Prosthodont 2013;22:53742.

[23] Zaruba M, Kasper R, Kazama R, Wegehaupt FJ, Ender A, Attin T, Mehl A. Marginal adaptation of ceramic and composite inlays in minimally invasive mod cavities. Clin Oral Investig 2014;18:579-87.

[24] Desai PD, Das UK. Comparison of fracture resistance of teeth restored with ceramic inlay and resin composite: an in vitro study. Indian J Dent Res 2011;22:877-92. [25] Meharry MR, Moazzami SM, Li Y. Comparison of enamel and dentin shear bond strengths of current dental bonding adhesives from three bond generations. Oper Dent 2013;38:E237-45.

[26] Pashley EL, Comer RW, Simpson MD, Horner JA, Pashley DH, Caughman WF. Dentin permeability: sealing the dentin in crown preparations. Oper Dent 1992;17:13-20. [27] Duarte S Jr, de Freitas CR, Saad JR, Sadan A. The effect of immediate dentin sealing on the marginal adaptation and bond strengths of total-etch and self-etch adhesives. J Prosthet Dent 2009;102:1-9.

[28] Oliveira L, Mota EG, Borges GA, Burnett LH Jr, Spohr AM. Influence of immediate dentin sealing techniques on cuspal deflection and fracture resistance of teeth restored with composite resin inlays. Oper Dent 2014;39:72-80.

[29] Paul SJ, Scharer P. The dual bonding technique: a modified method to improve adhesive luting procedures. Int J Periodontics Restorative Dent 1997;17:536-45.

[30] Kitasako Y, Burrow MF, Nikaido T, Tagami J. Effect of resin-coating technique on dentin tensile bond strengths over 3 years. J Esthet Restor Dent 2002;14:115-22.

[31] Duarte RM, de Goes MF, Montes MA. Effect of time on tensile bond strength of resin cement bonded to dentine and low-viscosity composite. J Dent 2006;34:52-61.

[32] Magne P, So WS, Cascione D. Immediate dentin sealing supports delayed restoration placement. J Prosthet Dent 2007;98:166-74. 
[33] Lee JI, Park SH. The effect of three variables on shear bond strength when luting a resin inlay to dentin. Oper Dent 2009;34:288-92.

[34] Choi YS, Cho IH. An effect of immediate dentin sealing on the shear bond strength of resin cement to porcelain restoration. J Adv Prosthodont 2010;2:39-45.

[35] Magne P. Immediate dentin sealing: a fundamental procedure for indirect bonded restorations. J Esthet Restor Dent 2005;17:144-55.

[36] Stoll R, Cappel I, Jablonski-Momeni A, Pieper K, Stachniss V. Survival of inlays and partial crowns made of IPS empress after a 10-year observation period and in relation to various treatment parameters. Oper Dent 2007;32:556-63.

[37] Frankenberger R, Taschner M, Garcia-Godoy F, Petschelt A, Kramer N. Leucitereinforced glass ceramic inlays and onlays after 12 years. J Adhes Dent 2008;10:393-8. [38] Gresnigt MM, Cune MS, de Roos JG, Özcan M. Effect of immediate and delayed dentin sealing on the fracture strength, failure type and Weilbull characteristics of lithiumdisilicate laminate veneers. Dent Mater 2016;32:e73-81.

[39] Naeije M. Craniomandibulaire functie en disfunctie. Bohn Stafleu Van Loghum; 1998. p. 39-56.

[40] Batalha-Silva S, de Andrada MA, Maia HP, Magne P. Fatigue resistance and crack propensity of large MOD composite resin restorations: direct versus CAD/CAM inlays. Dent Mater 2013;29:324-31.

[41] Heintze SD. How to qualify and validate wear simulation devices and methods. Dent Mater 2006;22:712-34.

[42] Özcan M, Barbosa SH, Melo RM, Galhano GA, Bottino MA. Effect of surface conditioning methods on the microtensile bond strength of resin composite to composite after aging conditions. Dent Mater 2007;23:1276-82.

[43] Kois DE, Isvilanonda V, Chaiyabutr Y, Kois JC. Evaluation of fracture resistance and failure risks of posterior partial coverage restorations. J Esthet Restor Dent 2013;25:110-22. 
[44] Heintze SD, Cavalleri A, Forjanic M, Zellweger G, Rousson V. Wear of ceramic and antagonist--a systematic evaluation of influencing factors in vitro. Dent Mater 2008;24:433-49.

[45] May LG, Passos SP, Capelli DB, Özcan M, Bottino MA, Valandro LF. Effect of silica coating combined to a MDP-based primer on the resin bond to Y-TZP ceramic. J Biomed Mater Res B Appl Biomater. 2010;95:69-74.

[46] Magne P, Douglas WH. Porcelain veneers: dentin bonding optimization and biomimetic recovery of the crown. Int J Prosthodont 1999;12:111-21.

[47] Peumans M, De Munck J, Fieuws S, Lambrechts P, Vanherle G, Van Meerbeek B. A prospective ten-year clinical trial of porcelain veneers. J Adhes Dent 2004;6:65-76.

[48] Beier US, Kapferer I, Burtscher D, Dumfahrt H. Clinical performance of porcelain laminate veneers for up to 20 years. Int J Prosthodont 2012;25:79-85. 


\section{Captions to tables and figures:}

\section{Tables:}

Table 1. The brands, types, chemical compositions, manufacturers and batch numbers of the main materials used in this study.

Table 2. Fracture strength results (Mean \pm standard deviation) (Newton) of experimental groups after thermo-mechanical aging and axial loading, minimum, maximum and Confidence Intervals (95\%). Same lower-case letters in each column indicate no significant differences within each column ( $p>0.05)$. For group descriptions see Fig. 1.

Table 3. Frequencies of failure modes after fracture test. Score 1: Fracture of the inlay; Score 2: Fracture of the inlay and enamel; Score 3: Fracture of the inlay, enamel and dentin, Score 4: Root fracture.

\section{Figures:}

Fig. 1. Flow-chart showing experimental sequence and allocation of groups.

Fig. 2 Probability plot with Weibull curves $(95 \% \mathrm{Cl})$ using maximum likelihood estimation, scale and shape values for all groups. 1: L-IDS', 2: L-IDS+ ${ }^{+}, 3:$ MR-IDS', 4: MR-IDS ${ }^{+}$

Figs. 3a-b. SEM images of inlays after thermo-mechanical aging from occlusal surfaces a) Lithium disilicate ceramic. Note the air-bubbles $\left({ }^{* *}\right)$ after the wear of the glaze layer $\left({ }^{*}\right)$, b) Multiphase resin composite. Note the extensive wear $\left(^{+}\right)$with small chippings on the occlusal surface $\left(^{++}\right)$.

Figs. 4a-b. SEM images of a representative specimen from a) group L-IDS ${ }^{+}$. Note the fractured inlay $\left(^{*}\right)$ with the IDS (Immediate Dentin Sealing) layer $\left(^{* *}\right)$ on the dentin surface $\left({ }^{* * *}\right)$, b) group MR-IDS ${ }^{+}$. Note the interface between MR $\left({ }^{+}\right)$and IDS $\left({ }^{++}\right)$. 
Tables:

\begin{tabular}{|c|c|c|c|c|}
\hline Brand & Type & Manufacturer & Composition & Batch number \\
\hline Clearfil SE Bond: Primer & Primer & Kuraray Co., Tokyo, Japan & $\begin{array}{l}\text { 10-Methacryloyloxydecyl } \\
\text { dihydrogenphosphate (MDP), 2- } \\
\text { Hydroxyethyl methacrylate (HEMA), } \\
\text { Hydrophilic dimethacrylate, dl- } \\
\text { Camphorquinone, N, N-di-ethanol-p- } \\
\text { toluidine, water }\end{array}$ & 200022 \\
\hline Clearfil SE Bond: Bond & Bonding & Kuraray Co. & $\begin{array}{l}\text { 10-Methacryloyloxydecyl } \\
\text { dihydrogenphosfate (MDP), } \\
\text { Bisphenol A diglycidylmethacrylate } \\
\text { (bis-GMA), 2-Hydroxyethyl } \\
\text { methacrylate (HEMA), Hydrophobic } \\
\text { dimethylacrylate, dl- } \\
\text { Camphorquinone, N, N-di-ethanol-p- } \\
\text { toluidine, Silanised colloidal silica }\end{array}$ & $2 T 0038$ \\
\hline Tetric Evoflow & Flowable composite & $\begin{array}{l}\text { Ivoclar Vivadent, Schaan, } \\
\text { Liechtenstein }\end{array}$ & $\begin{array}{l}\text { Dimethacrylates ( } 38 \% \mathrm{wt}) \text {, barium } \\
\text { glass, ytterbium trifluoride, highly } \\
\text { dispersed silicon dioxide, mixed } \\
\text { oxide and copolymer ( } 62 \% \text { wt). } \\
\text { Additives, catalysts, stabilizers and } \\
\text { pigments (<1\% wt). Particle size: } 40 \\
\text { nm }(0.04 \mu \mathrm{m})-3000 \mathrm{~nm}(3 \mu \mathrm{m}) . \\
\text { Mean particle size: } 550 \mathrm{~nm}(0.55 \mu \mathrm{m})\end{array}$ & S14454 \\
\hline Glycerin Gel & Glycerin gel & $\begin{array}{l}\text { Johnson \& Johnson, } \\
\text { Sezanne, France }\end{array}$ & Glycerin gel & 3099VA \\
\hline Durelon & Carboxylate cement & $\begin{array}{l}\text { 3M ESPE, St. Paul, } \\
\text { Minnesota, USA }\end{array}$ & $\begin{array}{l}\text { Powder: Zinc oxide, stannous } \\
\text { fluoride, tin dioxide. } \\
\text { Liquid: Water and polyacrylic acid }\end{array}$ & 525252 \\
\hline CoJet Sand & $\begin{array}{l}\text { Particle for air- } \\
\text { abrasion }\end{array}$ & 3M ESPE & $\begin{array}{l}\text { Aluminium trioxide particles coated } \\
\text { with silica, particle size: } 30 \mu \mathrm{m}\end{array}$ & $\begin{array}{l}446317 \\
446317\end{array}$ \\
\hline ESPE-Sil & Silane & 3M ESPE & $\begin{array}{l}\text { Ethyl alcohol, methacryloxypropyl, } \\
\text { trimethoxysilane }\end{array}$ & $\begin{array}{l}551520 \\
550016\end{array}$ \\
\hline Total-Etch & $\begin{array}{l}\text { Etching gel, } 37 \% \\
\text { Phosphoric acid }\end{array}$ & Ivoclar Vivadent & $37 \%$ phosphoric acid $\left(\mathrm{H}_{3} \mathrm{PO}_{4}\right)$ & T20546 \\
\hline Adhesive Universal & Bonding & Ivoclar Vivadent & $\begin{array}{l}\text { Methacrylates, ethanol, water, highly } \\
\text { dispersed silicon dioxide, initiators } \\
\text { and stabilizers }\end{array}$ & $\begin{array}{l}\text { T28040 } \\
\text { T24701 }\end{array}$ \\
\hline IPS Ceramic Etching Gel & $\begin{array}{l}<5 \% \text { Hydrofluoric } \\
\text { Acid }\end{array}$ & Ivoclar Vivadent & $<5 \%$ Hydrofluoric ccid & T19032 \\
\hline $\begin{array}{l}\text { IPS Ceramic Neutralizing } \\
\text { Powder }\end{array}$ & Neutralizing powder & Ivoclar Vivadent & $\begin{array}{l}25-50 \% \text { sodium carbonate, } 25-50 \% \\
\text { calcium carbonate }\end{array}$ & T11686 \\
\hline Monobond Plus & Silane & Ivoclar Vivadent & $\begin{array}{l}\text { Ethanol, 3-trimetho- } \\
\text { xysilsylpropylmetha-crylaat, } \\
\text { methacrylated phosphoric acid ester }\end{array}$ & $\begin{array}{l}\text { T07775 } \\
\text { T21454 }\end{array}$ \\
\hline Variolink Esthetic & $\begin{array}{l}\text { Dual cure resin } \\
\text { composite cement }\end{array}$ & Ivoclar Vivadent & $\begin{array}{l}\text { Monomers: Urethane dimethacrylate, } \\
\text { methacrylate. } \\
\text { Fillers: ytterbium trifluoride and } \\
\text { pheroid mixed oxide initiators, } \\
\text { stabilizers and pigments. Particle } \\
\text { size: } 0.04-0.2 \mu \text { m. Mean particle size: } \\
0.1 \mu \mathrm{m} \text {. Total volume of inorganic } \\
\text { fillers: approx. } 38 \% \text {. }\end{array}$ & $\begin{array}{l}\text { T15625 } \\
\text { T30447 }\end{array}$ \\
\hline Lava Ultimate & $\begin{array}{l}\text { Multiphase resin } \\
\text { composite (Shade } \\
\text { A2) }\end{array}$ & 3M ESPE & $\begin{array}{l}80 \% \text { nano ceramic components with } \\
20 \% \text { of polymer matrix }\end{array}$ & 498875 \\
\hline IPS e.max Press & $\begin{array}{l}\text { Lithiumdiscilicate } \\
\text { (Shade A2) }\end{array}$ & Ivoclar Vivadent & $\begin{array}{l}\mathrm{SiO}_{2}, \mathrm{Li}_{2} \mathrm{O}, \mathrm{K}_{2} \mathrm{O}, \mathrm{MgO}, \mathrm{ZnO}, \mathrm{Al}_{2} \mathrm{O}_{3} \\
\mathrm{P}_{2} \mathrm{O}_{5} \text { and other oxides }\end{array}$ & $\begin{array}{l}\text { R59340, } \\
\text { R64197, } \\
\text { R61630, } \\
\text { R70382 }\end{array}$ \\
\hline
\end{tabular}


Table 1. The brands, types, chemical compositions, manufacturers and batch numbers of the main materials used in this study.

\begin{tabular}{|c|c|c|c|c|c|c|}
\hline \multirow{2}{*}{$\begin{array}{c}\text { Experimental } \\
\text { Groups }\end{array}$} & \multirow[t]{2}{*}{$\mathbf{n}$} & \multirow[t]{2}{*}{ Mean (SD) } & \multirow[t]{2}{*}{ Minimum } & \multirow[t]{2}{*}{ Maximum } & \multicolumn{2}{|c|}{ Confidence Interval } \\
\hline & & & & & Lower Bound & $\begin{array}{l}\text { Upper } \\
\text { Bound }\end{array}$ \\
\hline L-IDS & 10 & $1358 \pm 506^{a}$ & 861 & 2362 & 2068.2 & 2788.1 \\
\hline L-IDS $^{+}$ & 10 & $2035 \pm 403^{b}$ & 1499 & 2799 & 2301.5 & 3048 \\
\hline MR-IDS- & 10 & $1861 \pm 423^{c}$ & 1238 & 2746 & 1199.6 & 1798.3 \\
\hline MR-IDS $^{+}$ & 10 & $1702 \pm 596^{c}$ & 891 & 2644 & 993.6 & 1241.6 \\
\hline
\end{tabular}

Table 2. Fracture strength results (Mean \pm standard deviation) (Newton) of experimental groups after thermomechanical aging and axial loading, minimum, maximum and Confidence Intervals (95\%). Same lower-case letters in each column indicate no significant differences within each column $(p>0.05)$. For group descriptions see Fig. 1.

\begin{tabular}{|l|c|c|c|c||c|c||c|}
\cline { 2 - 8 } \multicolumn{1}{c|}{} & \multicolumn{3}{c|}{ Failure types } & \multicolumn{2}{c|}{ IDS present on tooth } \\
\hline & Score 1 & Score 2 & Score 3 & Score 4 & Yes & No & N \\
\hline L-IDS $^{-}$ & & 8 & & & 4 & 4 & 8 \\
\hline L-IDS $^{+}$ & 1 & 3 & 3 & 3 & 10 & 0 & 10 \\
\hline MR-IDS $^{-}$ & 2 & 2 & 5 & 1 & 4 & 6 & 10 \\
\hline MR-IDS $^{+}$ & 4 & 2 & 2 & 2 & 10 & 0 & 10 \\
\hline
\end{tabular}

Table 3. Frequencies of failure modes after fracture test. Score 1: Fracture of the inlay; Score 2: Fracture of the inlay and enamel; Score 3: Fracture of the inlay, enamel and dentin, Score 4: Root fracture. 


\section{Figures:}

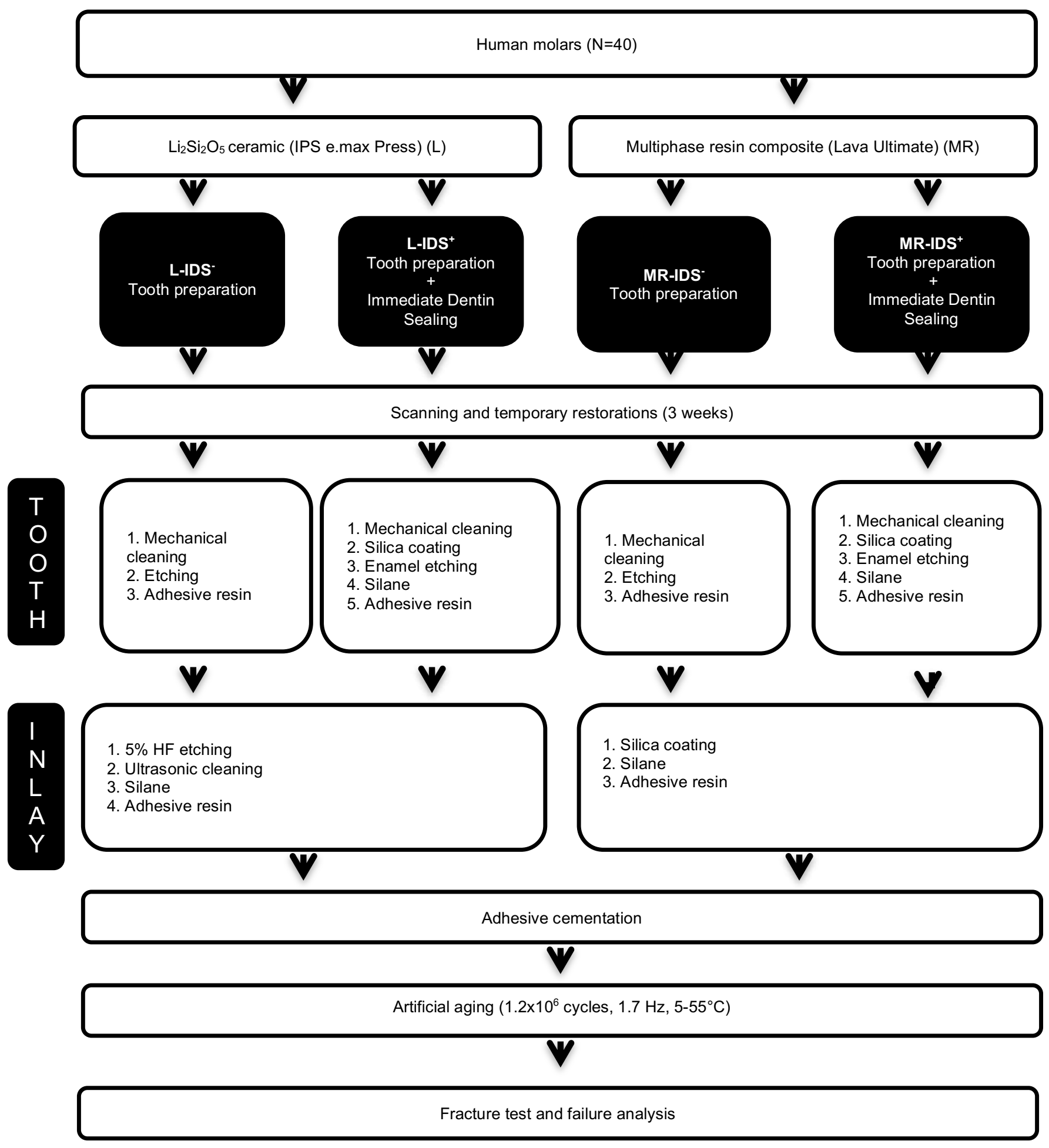

Fig. 1. Flow-chart showing experimental sequence and allocation of groups. 


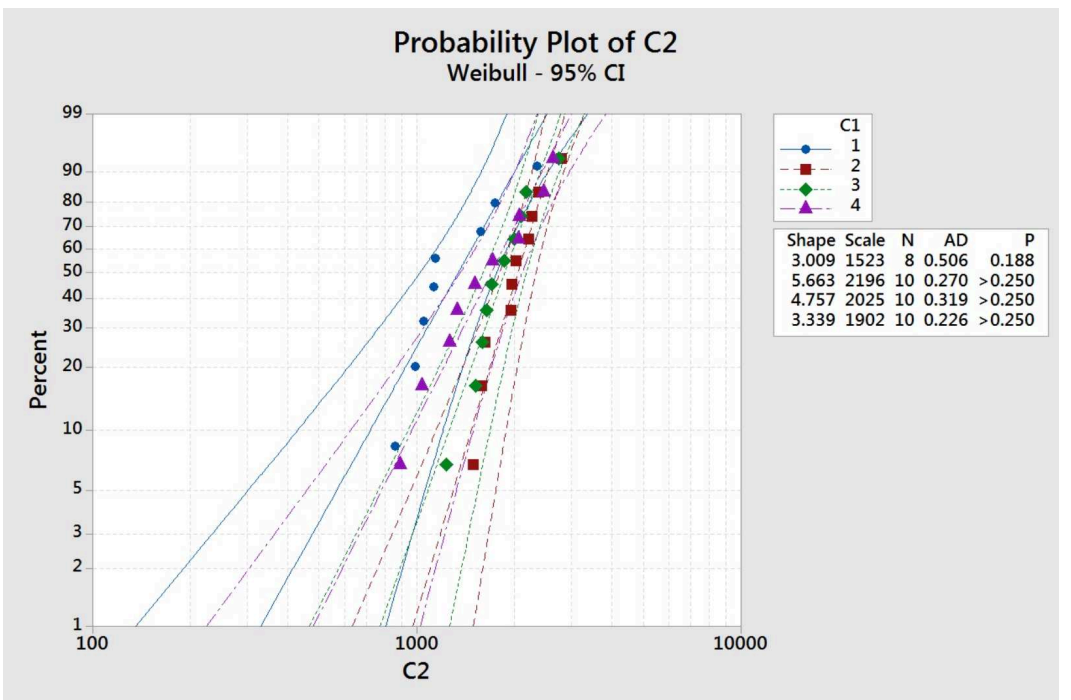

Fig. 2 Probability plot with Weibull curves $(95 \% \mathrm{Cl})$ using maximum likelihood estimation, scale and shape values for all groups. 1: L-IDS', 2: L-IDS+ ${ }^{+}$, MR-IDS', 4: MR-IDS $^{+}$.

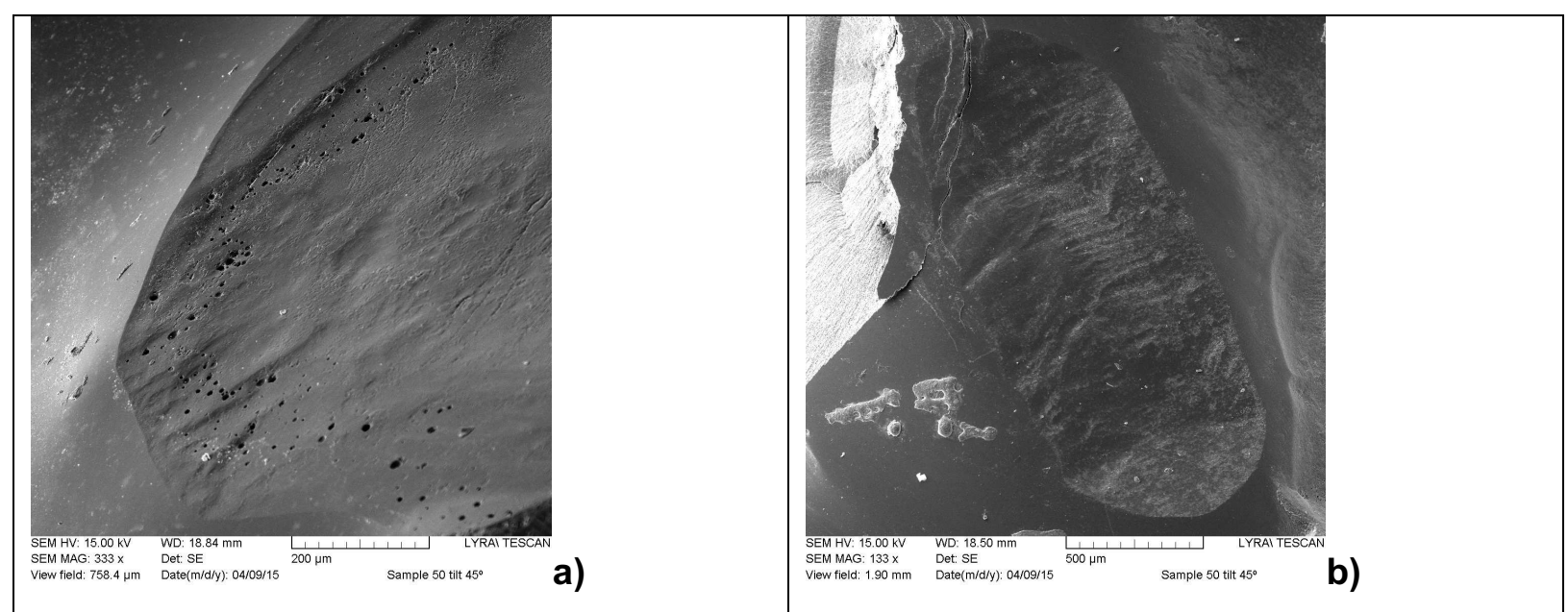

Figs. 3a-b. SEM images of inlays after thermo-mechanical aging from occlusal surfaces a) Lithium disilicate ceramic. Note the air-bubbles $\left({ }^{* *}\right)$ after the wear of the glaze layer $\left({ }^{\star}\right)$, b) Multiphase resin composite. Note the extensive wear $\left(^{+}\right)$with small chippings on the occlusal surface $\left(^{++}\right)$. 

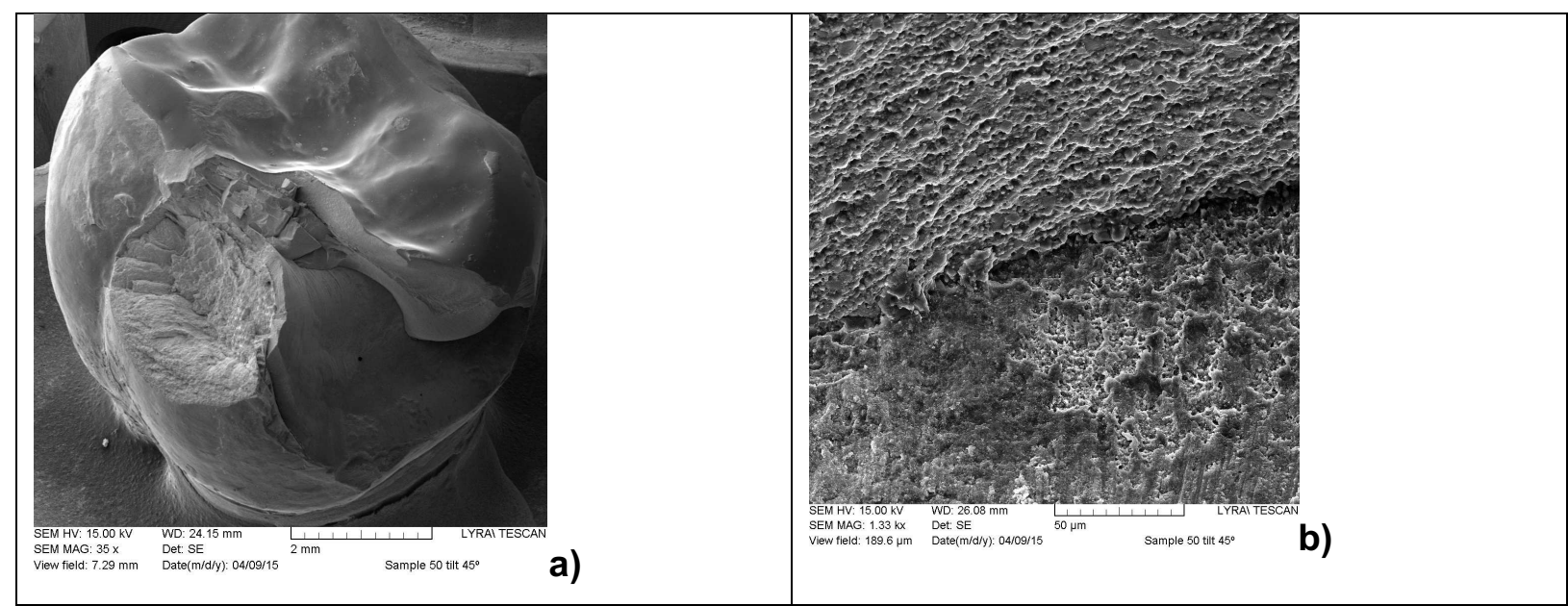

Figs. 4a-b. SEM images of a representative specimen from a) group L-IDS ${ }^{+}$. Note the fractured inlay $\left({ }^{\star}\right)$ with the IDS (Immediate Dentin Sealing) layer $\left({ }^{* *}\right)$ on the dentin surface $\left({ }^{* * *}\right)$, b) group MR-IDS ${ }^{+}$. Note the interface between MR $\left(^{+}\right)$and IDS $\left(^{++}\right)$. 